\title{
Satellite observations of the small-scale cyclonic eddies in the western South China Sea
}

\author{
F. Liu ${ }^{1}$, S. Tang ${ }^{2}$, and C. Chen ${ }^{2}$ \\ ${ }^{1}$ School of Marine Sciences, Sun Yat-sen University, Guangzhou 510006, China \\ ${ }^{2}$ State Key Laboratory of Tropical Oceanography, South China Sea Institute of Oceanology, Chinese Academy of Sciences, \\ Guangzhou 510301, China \\ Correspondence to: S. Tang (sltang2009@gmail.com)
}

Received: 8 August 2014 - Published in Biogeosciences Discuss.: 19 September 2014

Revised: 18 November 2014 - Accepted: 1 December 2014 - Published: 16 January 2015

\begin{abstract}
High-resolution ocean color observations offer an opportunity to investigate the oceanic small-scale processes. In this study, the Medium Resolution Imaging Spectrometer (MERIS) daily $300 \mathrm{~m}$ data were used to study small-scale processes in the western South China Sea. It is indicated that the cyclonic eddies with horizontal scales of $10 \mathrm{~km}$ are frequently observed during the upwelling season of each year over the 2004-2009 period. These small-scale eddies were generated in the vicinity of the southern front of the cold tongue, and then propagated eastward with a speed of approximately $12 \mathrm{~cm} \mathrm{~s}^{-1}$. This propagation speed was consistent with the velocity of the western boundary current. As a result, the small-scale eddies kept the high levels of phytoplankton rotating away from the coastal areas, resulting in the accumulation of phytoplankton in the interior of the eddies. The generation of the small-scale eddies may be associated with strengthening of the relative movement between the rotation speed of the anticyclonic mesoscale eddies and the offshore transport. With the increases of the normalized rotation speed of the anticyclonic mesoscale eddies relative to the offshore transport, the offshore current became a meander under the impacts of the anticyclonic mesoscale eddies. The meandered cold tongue and instability front may stimulate the generation of the small-scale eddies. Unidirectional uniform wind along the cold tongue may also contribute to the formation of the small-scale eddies.
\end{abstract}

\section{Introduction}

Approximately $90 \%$ of the kinetic energy of ocean circulation is contained in small-scale features, and $50 \%$ of the vertical exchange of water mass properties between the upper and the deep ocean may occur at the submesoscale and mesoscale (Bouffard et al., 2012). Mesoscale eddies with horizontal scales of $50-500 \mathrm{~km}$ can be observed using altimeters. However, the smaller-scale eddies (with horizontal scales below $50 \mathrm{~km}$ ) cannot be resolved by conventional altimeters (Liu et al., 2008). Satellite ocean color sensors provide high-quality observations of the bio-optical constitute at a spatial resolution better than from altimeters. The spatial resolutions of most ocean color satellites fall in the range from $300 \mathrm{~m}$ to $1.1 \mathrm{~km}$ (at nadir viewing). The high-resolution bio-optical observations reveal more details of small-scale phytoplankton structures. By tracking these small-scale biological features, one can determine the circulation pattern if the motion speed is large with respect of the growth and grazing of the phytoplankton (Pegau et al., 2002). Recently, the Medium Resolution Imaging Spectrometer (MERIS) fullresolution (FR, $300 \mathrm{~m})$ data set is available publicly. The MERIS FR $(300 \mathrm{~m})$ phytoplankton fields are rich in smallerscale biological features and provide opportunities to study the small-scale processes. Generally, the time period of the small-scale ocean variability ranges from several days to several weeks. However, the widely used ocean color data are usually averaged into weekly or monthly products in order to obtain a large spatial coverage. This time-averaging may smooth the phytoplankton variability on day-scale (Genin and Boehlert, 1985). Therefore, the study of the small-scale 

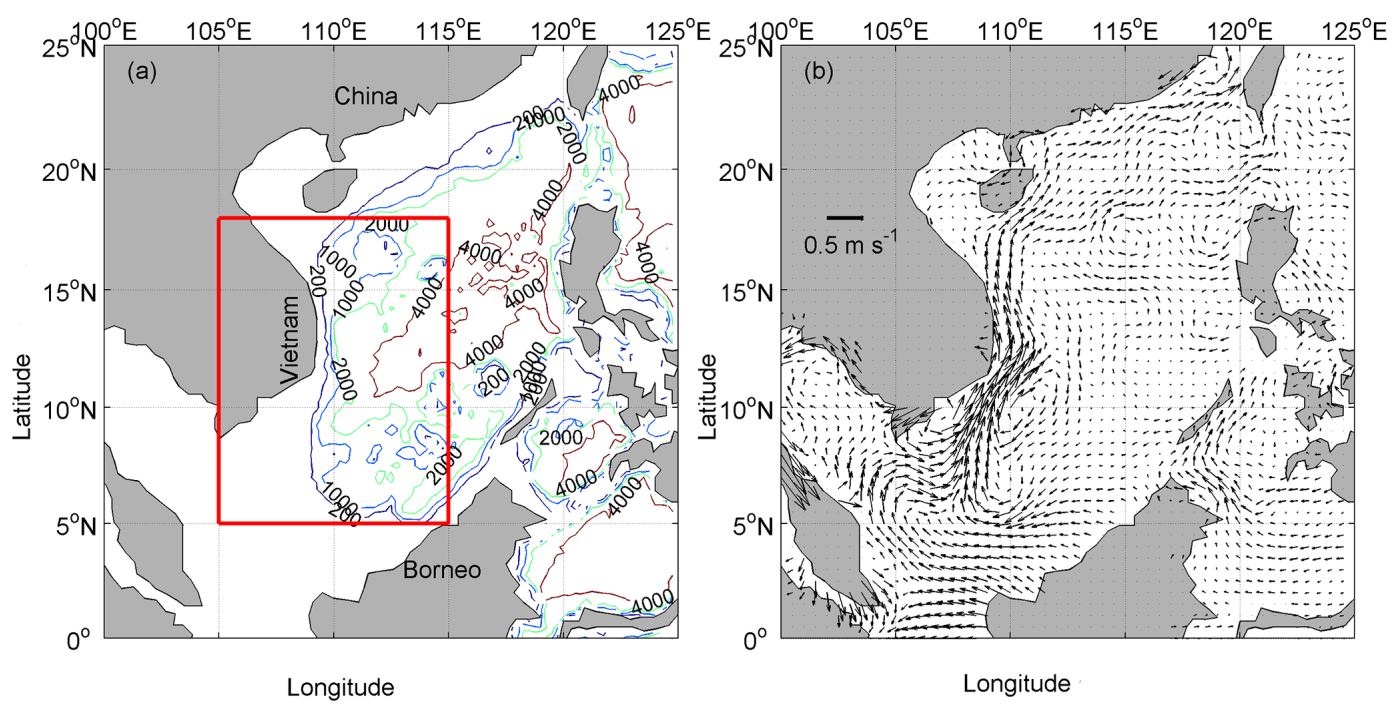

Figure 1. (a) Bathymetry of the South China Sea (m), the red rectangle represents the study area. (b) Mean surface geostrophic currents in June-October of 2002-2008.

processes requires higher space-time resolution of ocean color observation.

The South China Sea (SCS) is the largest marginal basin within the western Pacific, with a total area of 3.5 million square kilometers and a basin depth of $>3000 \mathrm{~m}\left(0^{\circ}-25^{\circ} \mathrm{N}\right.$, $100^{\circ}-125^{\circ}$ E, Fig. 1). The SCS is oligotrophic with limited nitrogen and phosphorus within the euphotic layer. A high abundance of phytoplankton mainly occurs in the Gulf of Tonkin, the western SCS and the Sunda Shelf in summer (Ning et al., 2004). It was reported that a phytoplankton filament in the western SCS is consistent with the mesoscale eddies transportation and Ekman upwelling (Tang et al., 2004; Xie et al., 2003; Xiu and Chai, 2011). However, there have been only limited studies on the small-scale process and its phytoplankton footprints (Nicholson, 2012). In this study, the daily MERIS FR data were used to identify the phytoplankton variability associated with the small-scale dynamic processes. In this paper, we will call eddies with diameters smaller than $50 \mathrm{~km}$ the small-scale eddies although, in the literature, they are often called submesoscale eddies (Bassin et al., 2005; Burrage et al., 2009).

The western SCS is one of the dynamically active regions in the SCS (Liu et al., 2000). A northeastward alongshore current in summer (Fig. 1) and a southwestward alongshore current in winter off the east coast of Vietnam are in accordance with wind stress (Hwang and Chen, 2000; Morimoto et al., 2000; Yuan et al., 2005). The northeastward alongshore current meanders off the southeastern coast of Vietnam and leaves the Vietnam coast forming an eastward current driven by the southwest wind paralleled to the coast of eastern Vietnam (Hwang and Chen, 2000; Kuo et al., 2000; Barthel et al., 2009). The southwesterly monsoon and Ekman transport drive seasonal upwelling off southeastern Vietnam coast in summer, leading to more than $1^{\circ} \mathrm{C}$ drop in sea surface temperature (SST) (Wyrtki, 1961; Kuo et al., 2000; Metzger, 2003; Tang et al., 2006). A cold SST tongue around $12^{\circ} \mathrm{N}$ extends eastward. The orographic effect of the coastal mountain ridge in Vietnam can further intensify the southwesterly wind and, thus, significantly enhances the coastal upwelling (Xie et al., 2003, 2007). The local orographic wind forces the coastal jet separation. This deformation and movement of coastal water induce mesoscale eddy activities (Gan et al., 2006; Wang et al., 2008; Chen et al., 2010). An eddy pair in the western SCS during the upwelling season is generated probably due to the vorticity transports from the nonlinear effect of the western boundary currents (Xie et al., 2003; Ning et al., 2004; Wang et al., 2006; Chen et al., 2010). Moreover, a pair of anticyclonic eddies (A-A eddy pairs) in the western SCS during the upwelling season was mentioned by Kuo et al. (2000) and Xie et al. (2003).

\section{Data}

The study area is located in the western SCS, covering $5^{\circ}$ $18^{\circ} \mathrm{N}, 105^{\circ}-115^{\circ} \mathrm{E}$ (Fig. 1). The daily MERIS FR chlorophyll data from 2004 to 2009 were obtained from the European Space Agency (ESA). The daily $1 \mathrm{~km}$ Moderateresolution Imaging Spectroradiometer (MODIS) SST data were obtained from National Aeronautics and Space Administration (NASA) Ocean Color project.

The mean sea level anomaly (MSLA) and geostrophic velocity data used here were extracted from the Delayed Time reference series provided by Archiving, Validation and Interpretation of Satellite Data in Oceanography (AVISO). The mesoscale eddies were identified by a new SSH-based (sea surface height) method developed by Chelton et al. (2011). 

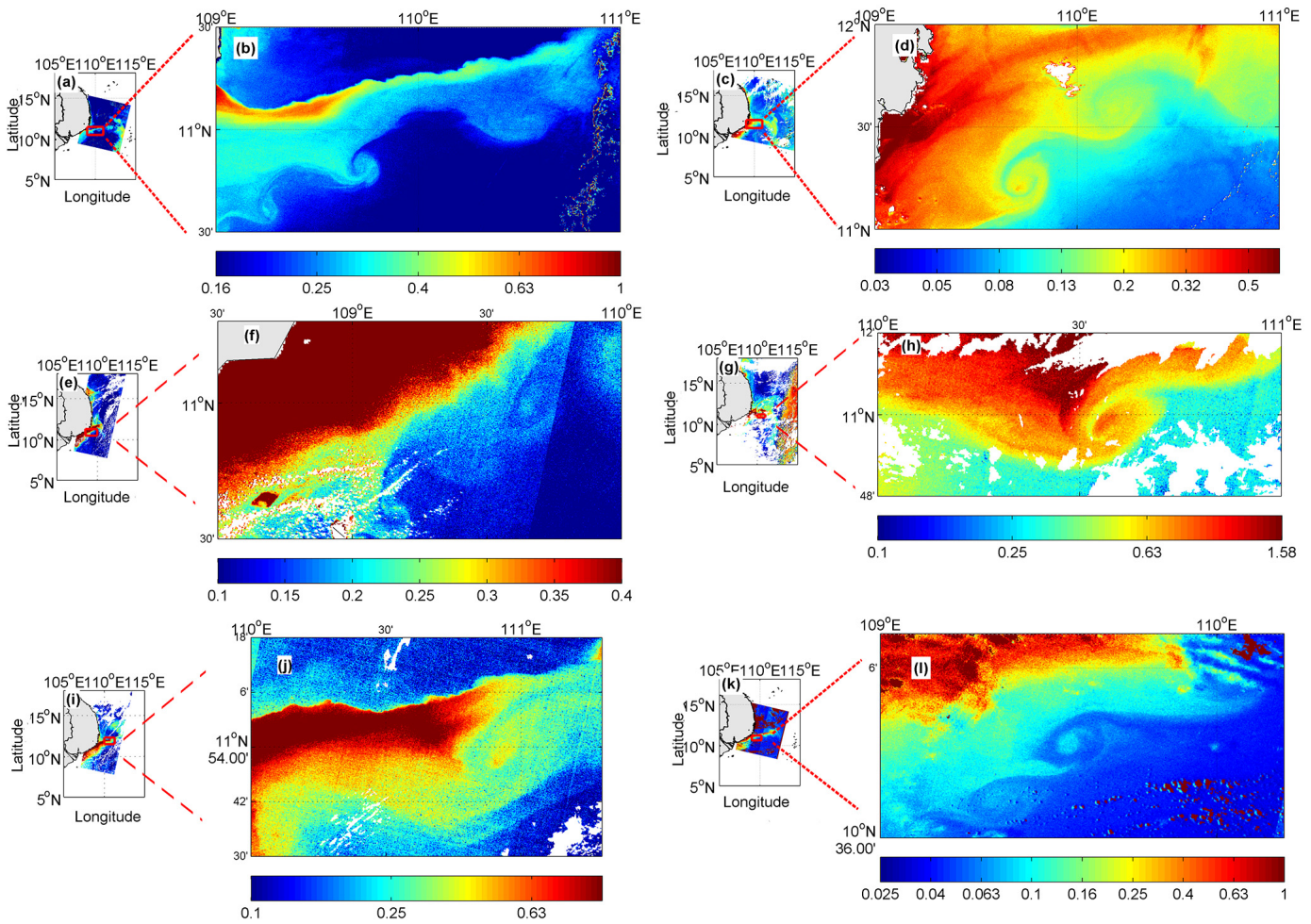

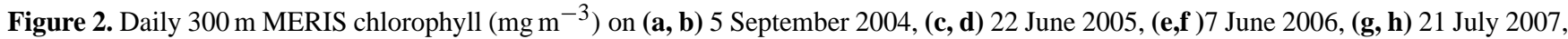
(i, j) 16 July 2008, (k, l) 29 July 2009. The cloud covered area was masked by the white color.

Rotational speed was computed as

$U=g f^{-1} A / L_{\mathrm{s}}$,

where $g$ is the gravitational acceleration, $f$ is the Coriolis parameter, $A$ is the eddy amplitude (in centimeters) and $L_{\mathrm{s}}$ is the eddy length scale (in kilometers), defined by the radius of the circle that has the same area as the region within the closed contour of MSLA with maximum average geostrophic current speed (Chelton et al., 2011).

The wind stress was obtained from the National Oceanic and Atmospheric Administration (NOAA) Environmental Research Division's Data Access Program (ERDDAP). The offshore transport $(M x)$ was calculated from

$M x=\tau_{y} / f$,

where $\tau_{y}$ is the wind stress parallel to the coastline, positive in the northward direction. This was replaced with the meridional direction wind stress since the most significant offshore transport perpendicular to the Vietnam coast is approximately in the zonal direction.

\section{Results and discussion}

A series of small cyclonic phytoplankton tendrils at the southern edge of the phytoplankton filament were found dur- ing June and October of each year over the 2004-2009 period (Fig. 2). The phytoplankton tendrils had a mean diameter of $25 \mathrm{~km}$ and obviously rotated out of the filament as the concentration variability of the phytoplankton tendril seemed consistent with the phytoplankton filament concentration variability. It is implied that the phytoplankton tendril is rotated by the small-scale cyclonic eddy. High levels of phytoplankton were frequently observed in the center of the small-scale cyclonic eddies. The reason for this phenomenon will be discussed in the next section.

Figure 3 shows an evolution of two cyclonic phytoplankton tendrils during 9 July 2008 and 13 July 2008. It seems that these phytoplankton tendrils have a timescale of several days. The phytoplankton tendril A was less obvious on 9 July 2008. Three days later, the concentration of phytoplankton tendril A increased about $0.1 \mathrm{mg} \mathrm{m}^{-3}$. This high level of phytoplankton mainly occurred at the edge. The phytoplankton levels in the center were relatively low (approximately $0.07 \mathrm{mg} \mathrm{m}^{-3}$ ). Only 1 day later, the phytoplankton concentration in the center increased to approximately $0.3 \mathrm{mg} \mathrm{m}^{-3}$ and became greater than the level of phytoplankton at the periphery. Another feature was that the cyclonic A tended to propagate eastward. It propagated approximately $0.1^{\circ}(\sim 10 \mathrm{~km})$ from 12 July 2008 to 13 July 2008 . The western boundary current had a speed of about $12 \mathrm{~cm} \mathrm{~s}^{-1}$ $\left(10.4 \mathrm{~km} \mathrm{day}^{-1}\right)$ in the western SCS during summer (Cai et 


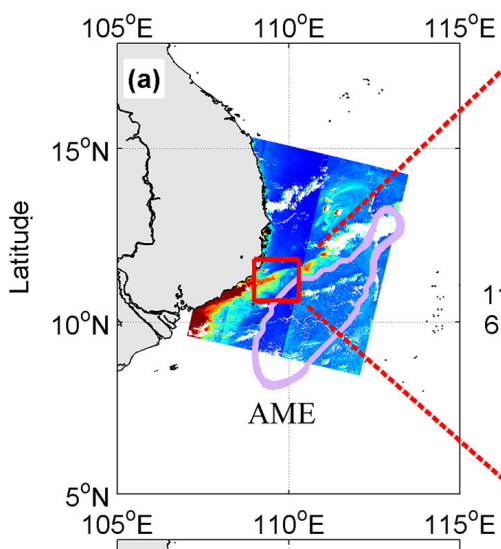

$109^{\circ} \mathrm{E}$ $110^{\circ} \mathrm{E}$
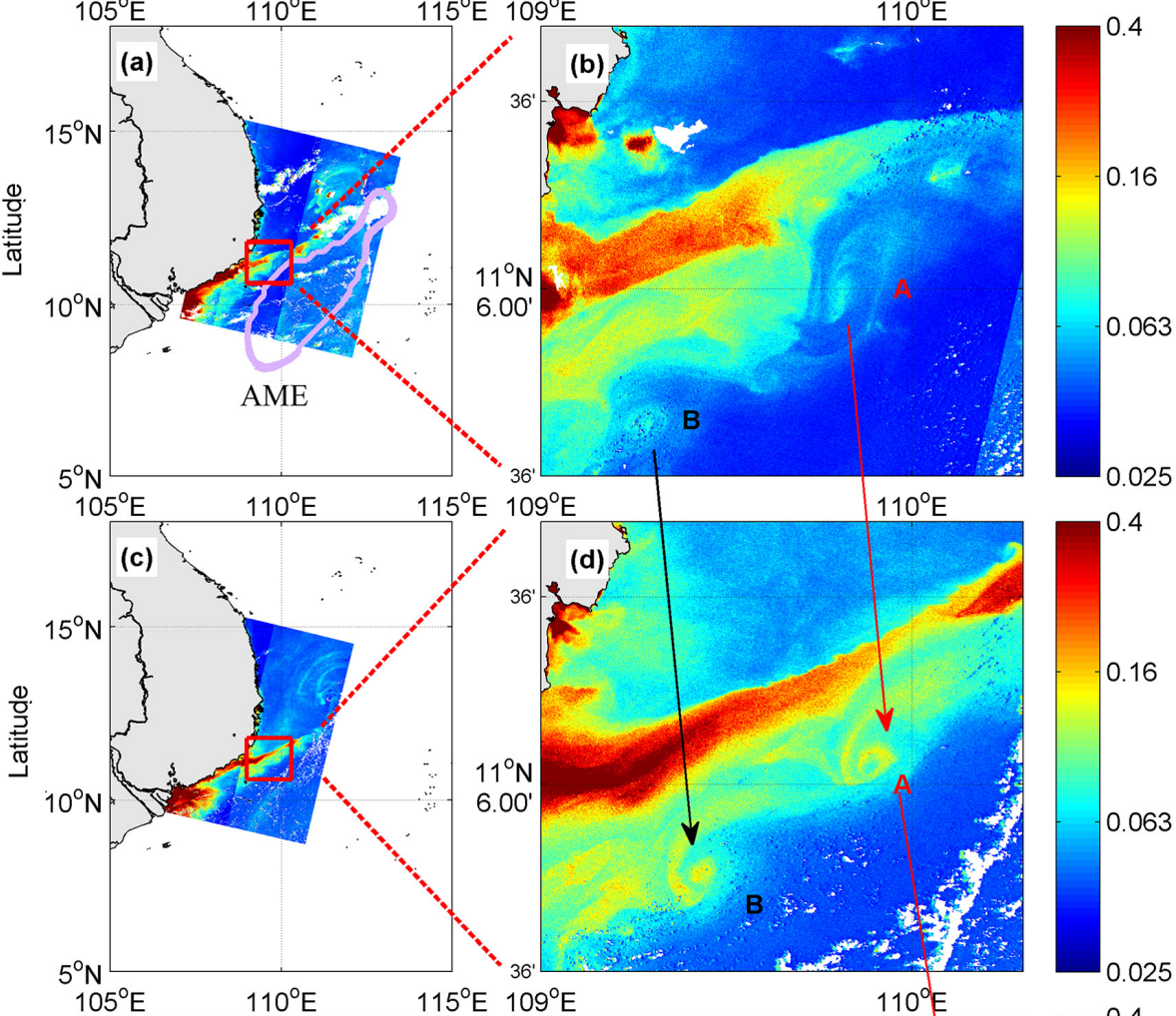

$110^{\circ} \mathrm{E}$
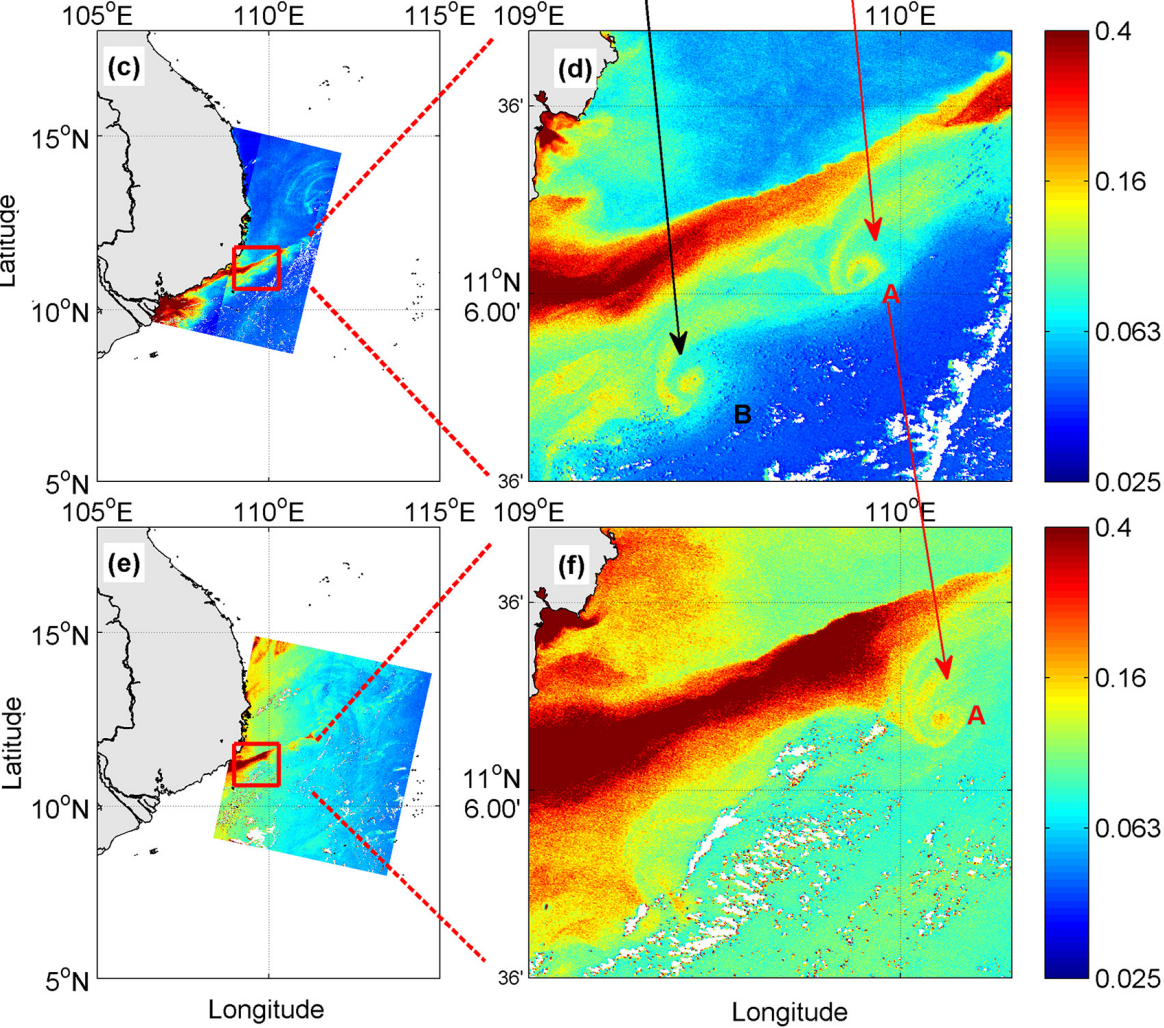

$110^{\circ} \mathrm{E}$

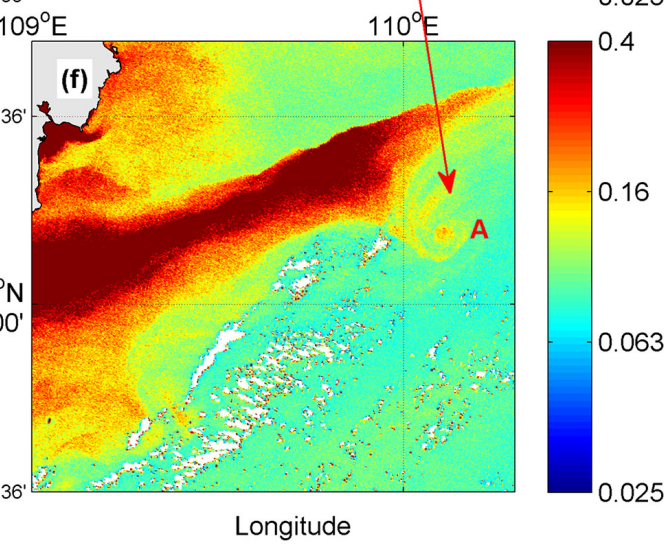

Figure 3. Daily $300 \mathrm{~m}$ MERIS chlorophyll $\left(\mathrm{mg} \mathrm{m}^{-3}\right)$ on (b) 9 July 2008, (c, d) 12 July 2008, and (e, f) 13 July 2008 . The cloud covered area was masked by the white color. A and B indicate two small cyclonic eddies, respectively. The pink circle in (a) denotes the anticyclonic mesoscale eddy (AME) on 9 July 2008, which was derived from AVISO MSLA data following the method of Chelton et al. (2011).

al., 2007), which was consistent with the propagation velocity of the small cyclonic eddy A. Therefore, the eastward propagating cyclonic eddy may be driven by the western boundary current. The small cyclonic eddy B strengthened on 12 July 2008, with high levels of phytoplankton within its interior, and then it disappeared on 13 July 2008.

The observation of more detailed phytoplankton distribution in the tendrils was attributed to the much finer resolution $(300 \mathrm{~m})$. We found that there were relatively high phytoplankton levels in the center of the small cyclonic eddies. One possible mechanism is that the small cyclonic eddies keep rotating high phytoplankton and perhaps nutrients, lead- ing to the accumulation of phytoplankton in their center. Another possible mechanism is that the vertical velocity of these small-scale cyclonic eddies may drive episodic nutrient pulses to the euphotic zone to stimulate phytoplankton growth (Lévy et al., 2012). Figure 4 shows the sea surface temperature distribution associated with the phytoplankton tendril A. It is obvious that the cold water was transported away from the cold tongue by the small-scale eddies, and that the low-temperature water firstly occurred in the periphery of the eddies. Different from the majority of mesoscale cyclonic eddies, there was no significantly lower-temperature water in the center. It is implied that there is no upwelling or 


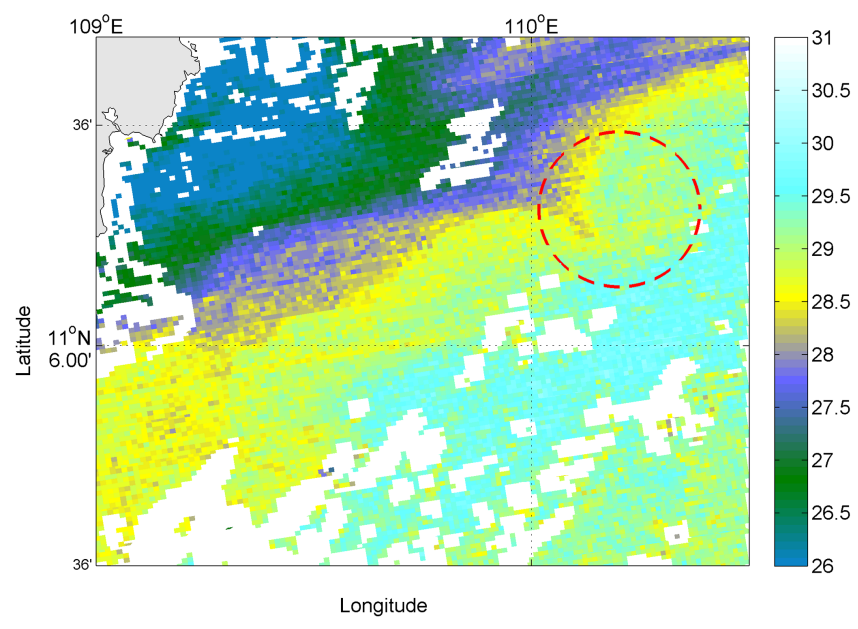

Figure 4. MODIS $1 \mathrm{~km}$ sea surface temperature distribution (unit: ${ }^{\circ}$ ) on 13 July 2008.

vertical mixing in the center. Therefore, the phytoplankton distribution over this small-scale eddy may be dominated by horizontal movement, and the relatively high phytoplankton level in the center of the cyclonic eddy A could be attributed to the accumulation of phytoplankton or nutrients from the outer edge to the interior under the rotation effect.

The small-scale eddies strengthened the horizontal diffusion of the nutrients and phytoplankton (Capet et al., 2008a). These small cyclonic eddies were mainly observed at the front of the filament, where strong differences in water mass properties resulted in high strain rates and instabilities. Meanwhile, the small-scale eddies were also associated with the occurrence of an anticyclonic mesoscale eddy to the south of the filament (Fig. 3a). However, the smallscale cyclonic eddy did not occur for the entire period of the offshore Ekman transport and the anticyclonic eddy. It only arose at certain stages. We analyzed the offshore Ekman transport $(M x)$ and rotation speed of the anticyclonic eddies during the development of the small-scale eddies over the period of July 2008 shown in Fig. 3. Due to the limits of the cloud coverage and satellite passing time, the image showing the declination of small-scale eddies was not available. However, it is found that the small-scale eddies disappeared on 22 July 2008. Figure $3 \mathrm{a}$ and b imply that the small-scale eddies may initially form on 9 July 2008 . Therefore, we presumed that the small-scale eddies occurred during 9-22 July. Figure 5 indicates that the offshore transport $(M x)$ decreased first and then increased rapidly on 16 July. Different from the variability of $M x$, the rotation speed increased from $0.33 \mathrm{~m} \mathrm{~s}^{-1}$ on 2 July to $0.42 \mathrm{~m} \mathrm{~s}^{-1}$ on $12 \mathrm{July}$, and then started to decrease to approximately $0.4 \mathrm{~m} \mathrm{~s}^{-1}$ on 16 July. Lastly, the rotation speed increased, which is associated with the strengthening of $M x$. The variability of $M x$ seemed not to be consistent with the variability of the levels of phytoplankton (Fig. 3). The levels of phytoplankton
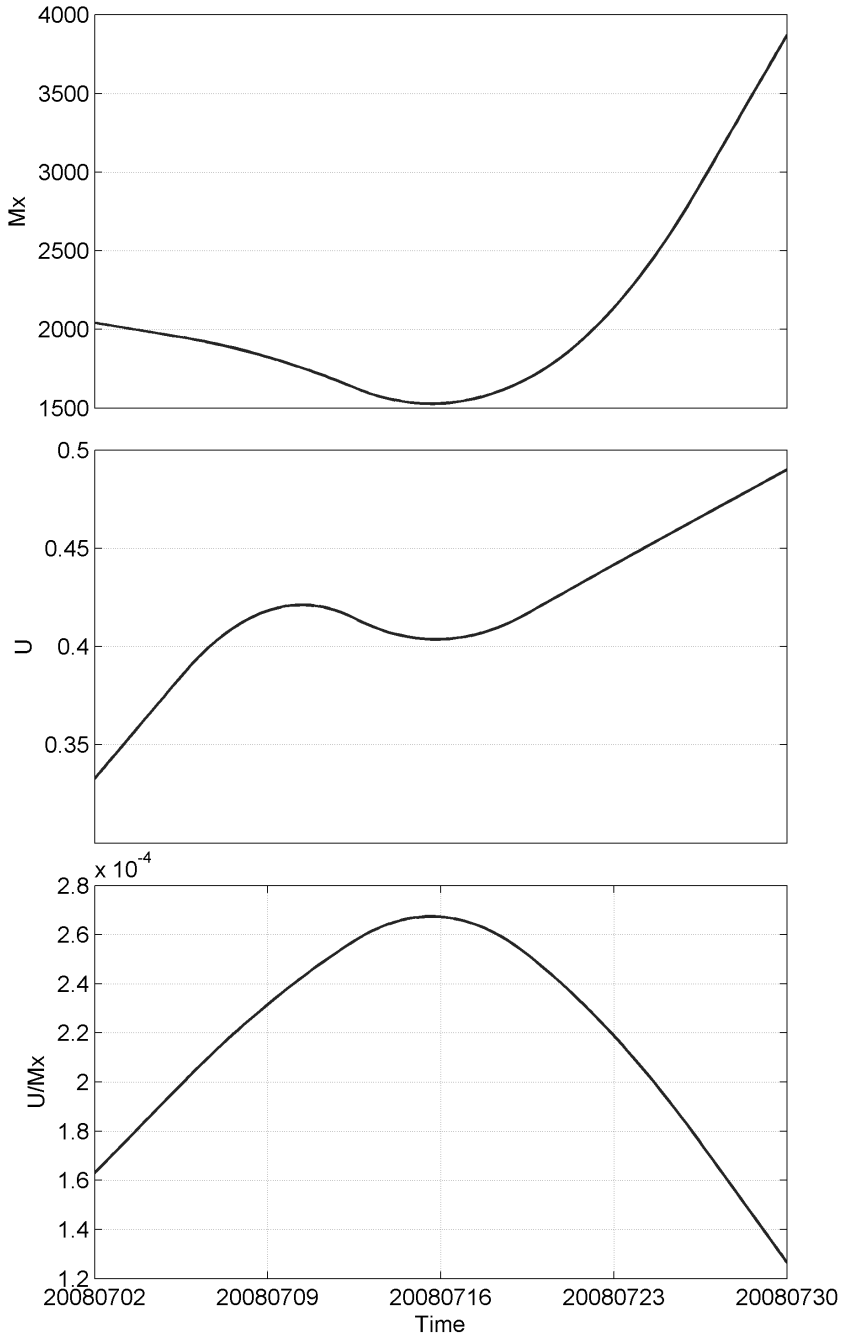

Figure 5. The offshore transport $\left(M x, \mathrm{~kg} \mathrm{~m}^{-1} \mathrm{~s}^{-1}\right)$, rotation speed of the mesoscale anticyclonic eddy $\left(U, \mathrm{~cm} \mathrm{~s}^{-1}\right)$ and the normalized rotation speed to $M x(U / M x)$, indicating the relative importance of the mesoscale anticyclonic eddy and offshore Ekman transport in the form of small-scale eddies.

had a significant increase from 9 July to 13 July, accompanying the decreases of $M x$. This may be due to a lag between nutrient inputs and phytoplankton growth. The normalized rotation speed of the anticyclonic eddy was defined as the ratio of the rotation speed and the $M x$, which indicated the relative movement between the anticyclonic eddy and the offshore transport. The variability of the normalized rotation speed shows that the small-scale eddies were associated with the greater relative movement between the anticyclonic eddy and the offshore transport (Fig. 5). The offshore current became a meander under the influence of the anticyclonic eddy when the offshore transport turned weaker and the rotation speed of the anticyclonic eddy increased. The meandering current may stimulate the generation of the small-scale process (Capet et al., 2008a, b). 


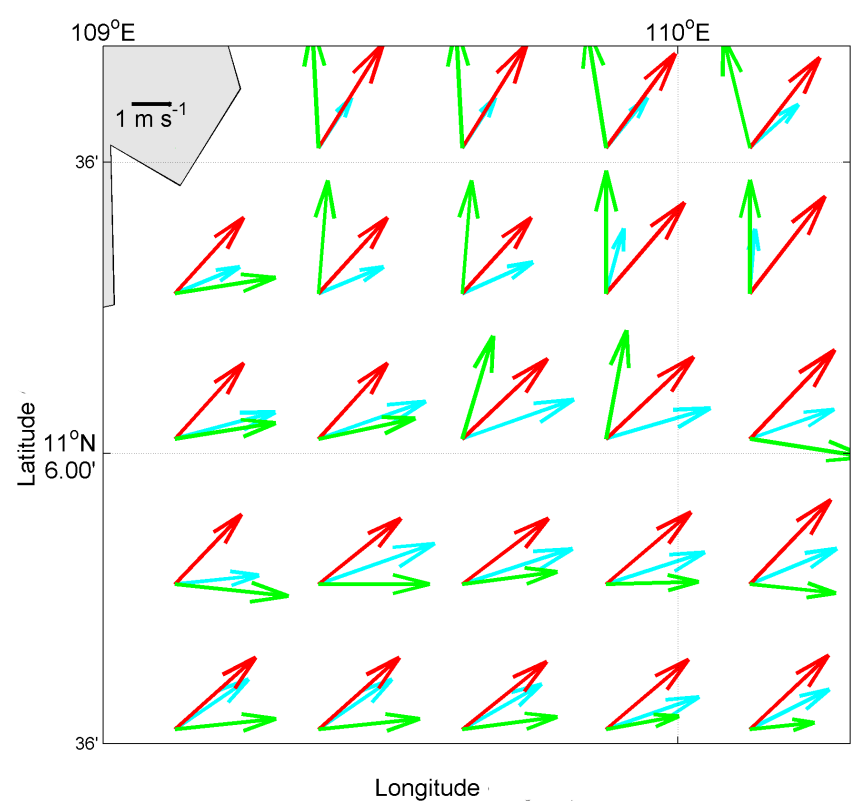

Figure 6. Wind fields on 2 July 2008 (blue arrows), 12 July 2008 (red arrows) and 26 July 2008 (green arrows).

The phytoplankton filament was consistent with the cold tongue induced by the offshore Ekman transport, which was associated with the negative sea surface height anomaly relative to the surrounding light and warm water. The smallscale eddies extended from the cold tongue along the front. Therefore, the heavy and cold water firstly occurred in the periphery of small-scale eddies. Along the front, the transport from the surface, heavy water to the light water may be forced by the wind. Throughout the development of the small-scale eddies, the wind direction exhibited some variations (Fig. 6). Wind direction varied from west-southwest (WSW) on 2 July 2008 (before the generation of the smallscale eddies) to southwest (SW) on 9-13 July 2008 (during the presence of the small-scale eddies). This implies that the small-scale eddies tend to be associated with the more unidirectional uniform wind blowing along the phytoplankton filament. Under spatially uniform wind forcing, the changed meandering current may be more likely to generate the smallscale structure (McGillicuddy et al., 2007; Mahadevan et al., 2008).

\section{Conclusions}

This paper describes the small-scale cyclonic eddies in the western SCS. Driven by the small-scale cyclonic eddies, a series of phytoplankton tendrils occurs at the southern front of the wind-driven offshore current. These small-scale eddies have a horizontal extent of less than $50 \mathrm{~km}$ and propagate eastward at the speed of $12 \mathrm{~cm} \mathrm{~s}^{-1}$, accompanying an offshore current. The offshore current, mesoscale anticyclonic eddies and wind field may contribute to the generation of the small-scale cyclonic eddies. Horizontal transport by the small-scale cyclonic eddies stimulates the diffusion of the nutrients and phytoplankton of the western SCS.

Acknowledgements. We gratefully thank Ruixin Huang and Ian Jones for helpful comments and suggestions. The MERIS $300 \mathrm{~m}$ chlorophyll data were provided by ESA-MOST Dragon 3 Cooperation Programme from the European Space Agency. The sea surface height and geostrophic current data were obtained from the Archiving Validation and Interpretation of Satellite Data in Oceanography. The MODIS sea surface temperature was obtained from the NASA ocean color project. The wind stress was obtained from the National Oceanic and Atmospheric Administration Environmental Research Division's Data Access Program. The research was supported by the Strategic Priority Research Program of the Chinese Academy of Sciences (no. XDA11010302), the Public science and technology research funds projects of ocean (no. 201205040-6), the Innovation Group Program of State Key Laboratory of Tropical Oceanography, South China Sea Institute of Oceanology, Chinese Academy of Sciences (no. LTOZZ1201) and the National Natural Science Foundation of China (no. 41006111).

Edited by: K. Suzuki

\section{References}

Barthel, K., Rosland, R., and Thai, N. C.: Modelling the circulation on the continental shelf of the province Khanh Hoa in Vietnam, J. Marine Syst., 77, 89-113, 2009.

Bassion, C. J., Washburn, L., Brzezinski, M., and McPhee-Shaw, E.: Sub-mesoscale coastal eddies observed by high frequency radar: A new mechanism for delivering nutrients to kelp forests in the Southern California Bight, Geophys. Res. Lett., 32, L12604, doi:10.1029/2005GL023017, 2005.

Bouffard, J., Renault, L., Ruiz, S., Pascual, A., Dufau, C., and Tintoré, J.: Sub-surface small-scale eddy dynamics from multisensor observations and modeling, Progr. Oceanogr., 106, 62-79, 2012.

Burrage, D. M., Book, J. W., and Martin, P. J.: Eddies and filaments of the Western Adriatic Current near Cape Gargano: Analysis and prediction, J. Marine Syst., 78, S205-S226, 2009.

Cai, S., Long, X., and Wang, S.: A model study of the summer Southeast Vietnam Offshore Current in the southern South China Sea, Cont. Shelf Res., 27, 2357-2372, 2007.

Capet, X., McWilliams, J. C., Molemaker, M. J., and Shchepetkin, A. F.: Mesoscale to submesoscale transition in the California Current System. Part I: Flow structure, eddy flux, and observational tests, J. Phys. Oceanogr., 38, 29-43, 2008a.

Capet, X., McWilliams, J. C., Molemaker, M. J., and Shchepetkin, A. F.: Mesoscale to submesoscale transition in the California Current System, Part II: Frontal processes, J. Phys. Oceanogr., 38, 44-64, 2008b.

Chelton, D. B., Schlax, M. G., and Samelson, R. M.: Global observations of nonlinear mesoscale eddies, Prog. Oceanogr., 91, 167-216, 2011. 
Chen, G., Hou, Y., Zhang, Q., and Chu, X.: The eddy pair off eastern Vietnam: Interannual variability and impact on thermohaline structure, Cont. Shelf Res., 30, 715-723, 2010.

Gan, J., Li, H., Curchitser, E. N., and Haidvogel, D. B.: Modeling South China Sea circulation: Response to seasonal forcing regimes, J. Geophys. Res., 111, C06034, doi:10.1029/2005JC003298, 2006.

Genin, A. and Boehlert, G. W.: Dynamics of temperature and chlorophyll structures above a seamount: An oceanic experiment, J. Marine Syst., 43, 907-924, 1985.

Huang, B., Hu, J., Xu, H., Cao, Z., and Wang D.: Phytoplankton community at warm eddies in the northern South China Sea in winter 2003/2004, Deep-Sea Res. Pt. II, 57, 1792-1798, 2010.

Hwang, C. and Chen S.-A.: Circulations and eddies over the South China Sea derived from TOPEX/Poseidon altimetry, J. Geophys. Res., 105, 23943-23965, 2000.

Kuo, N.-J., Zheng, Q., and Ho, C.-R.: Satellite Observation of Upwelling along the Western Coast of the South China Sea, Remote Sens. Environ., 74, 463-470, 2000.

Lévy, M., Ferrari, R., Franks, P. J. S., Martin, A. P., and Rivière, P.: Bringing physics to life at the submesoscale, Geophys. Res. Lett., 39, L14602, doi:10.1029/2012GL052756, 2012.

Liu, Y., Weisberg, R. H., and Yuan, Y.: Patterns of upper layer circulation variability in the South China Sea from satellite altimetry using the Self-Organizing Map, Acta Oceanol. Sin., 27 (Supplement), 129-144, 2008.

Liu, Y., Yuan, Y. ,Su, J., and Jiang, J.: Circulation in the South China Sea in summer of 1998, Chinese Sci. Bull., 45, 1648-1655, 2000.

Mahadevan, A., Thomas, L. N., and Tandon, A.: Comment on "eddy/wind interactions stimulate extraordinary mid-ocean plankton blooms", Science, 320, p. 448, 2008.

McGillicuddy, D. J., Anderson, L. A., Bates, N. R., Bibby, T., Buesseler, K. O., Carlson, C. A., Davis, C. S., Ewart, C., Falkowski, P. G., Goldthwait, S. A., Hansell, D. A., Jenkins, W. J., Johnson, R., Kosnyrev, V. K., Ledwell, J. R., Li, Q. P., Siegel, D. A., and Steinberg, D. K.: Eddy/wind interactions stimulate extraordinary mid-ocean plankton blooms, Science, 316, 1021-1026, 2007.

Metzger, E.: Upper Ocean Sensitivity to Wind Forcing in the South China Sea, J. Oceanogr., 59, 783-798, 2003.

Morimoto, A., Yoshimoto, K., and Yanagi, T.: Characteristics of sea surface circulation and eddy field in the South China Sea revealed by satellite altimetric data, J. Oceanogr., 3, 331-344, 2000.

Nicholson, S.: Linking small-scale circulation dynamics with large-scale seasonal production (phytoplankton) in the Southern Ocean, 4th CSIR Biennial Conference: Real problems relevant solutions, CSIR, Pretoria, 9-10 October 2012
Ning, X., Chai, F., Xue, H., Cai, Y., Liu, C., and Shi, J.: Physicalbiological oceanographic coupling influencing phytoplankton and primary production in the South China Sea, J. Geophys. Res., 109, C10005, doi:10.1029/2004JC002365, 2004.

Pegau, W., Boss, E., and Martínez, A.: Ocean color observations of eddies during the summer in the Gulf of California, Geophys. Res. Lett., 29, 1-3, 2002.

Tang, D. L., Kawamura, H., Shi, P., Takahashi, W., Guan, L., Shimada, T., Sakaida, F., and Isoguchi, O.: Seasonal phytoplankton blooms associated with monsoonal influences and coastal environments in the sea areas either side of the Indochina Peninsula, J. Geophys. Res., 111, G01010, doi:10.1029/2005JG000050, 2006.

Tang, D., Kawamura, H., Dien, T., and Lee, M.: Offshore phytoplankton biomass increase and its oceanographic causes in the South China Sea, Mar. Ecol. Prog. Ser. 268, 31-41, 2004.

Wang, G., Chen, D., and Su, J.: Generation and life cycle of the dipole in the South China Sea summer circulation, J. Geophys. Res., 111, C06002, doi:10.1029/2005JC003314, 2006.

Wang, G., Chen, D., and Su, J.: Winter Eddy Genesis in the Eastern South China Sea due to Orographic Wind Jets, J. Phy. Oceanogr., 38, 726-732, 2008.

Wyrtki, K.: Physical Oceanography of the Southeast Asian waters, NAGA Rep. 2, Scripps Inst. Oceanogr, La Jolla, Calif, 195 pp., 1961.

Xie, S.-P., Xie, Q., Wang, D., and Liu, W.T.: Summer upwelling in the South China Sea and its role in regional climate variations, J. Geophys. Res., 108, 3261, doi:10.1029/2003JC001867, 2003.

Xie, S.-P., Chang, C.-H., Xie, Q., and Wang D.: Intraseasonal variability in the summer South China Sea: Wind jet, cold filament, and recirculations, J. Geophys. Res., 112, C10008, doi:10.1029/2007JC004238, 2007.

Xiu, P. and Chai, F.: Modeled biogeochemical responses to mesoscale eddies in the South China Sea, J. Geophys. Res., 116, C10006, doi:10.1029/2010JC006800, 2011.

Yuan, Y., Liu, Y., Liao, G., Lou, R., Su, J., and Wang, K.: Calculation of circulation in the South China Sea during summer of 2000 by the modified inverse method, Acta Oceanol. Sin., 24, 14-30, 2005. 